\title{
Surgical treatment of chronic aortoiliac occlusion
}

\author{
Tratamento cirúrgico da oclusão crônica aorto-ilíaca
}

Márcio Luís Lucas ${ }^{1}$, Lúcia Deibler ${ }^{1}$ Nilon Erling Jr. ${ }^{1}$, Eduardo Lichtenfels ${ }^{1}$, Newton Aerts ${ }^{1}$

\begin{abstract}
Background: Chronic aortoiliac occlusion (CAIO) is a significant cause of lower limb ischemia and is often found in young patients who smoke. Objective: To review recent results achieved treating CAIO patients with open surgery. Methods: From November 2011 to April 2014, 21 patients with CAIO were treated at the Santa Casa de Misericórdia, Porto Alegre, Brazil. Demographic data, comorbidities, clinical presentation and surgical results were analyzed. Results: Eleven women and ten men were treated with direct aortic bypass (DAB; $n=18$ ) or with extra-anatomic bypass (EAD; $n=3$ ). Mean age was $53.7 \pm 7.3$ years (range: $43-79$ years) and all patients smoked. Thirteen patients $(62 \%)$ had critical ischemia. Six of the patients treated with DAB (33.4\%) also required additional revascularization (3 renal and 3 femoropopliteal procedures). Perioperative mortality was zero. Four patients (22.2\%) suffered transitory renal dysfunction, but only one patient (5.6\%) required hemodialysis. Median follow-up time was 17 months (range: 2-29 months) and there was just one late death, from ischemic heart disease, 7 months after the surgery on the abdominal aorta. Conclusions: Aortic reconstruction is a safe method for treating patients with CAIO, with low perioperative morbidity and mortality rates.
\end{abstract}

Keywords: abdominal aorta; thrombosis; surgical procedures.

\begin{abstract}
Resumo
Contexto: A oclusão crônica aorto-ilíaca (OCAI) é uma importante causa de isquemia dos membros inferiores e é frequentemente encontrada em pacientes jovens e tabagistas. Objetivo: Revisar os resultados recentes da cirurgia aberta em pacientes com OCAI. Métodos: Entre novembro de 2011 e abril de 2014, 21 pacientes com OCAI foram tratados na Santa Casa de Misericórdia de Porto Alegre. Foram analisados dados demográficos, comorbidades, apresentação clínica e resultados cirúrgicos. Resultados: Onze mulheres e dez homens foram tratados com derivação aórtica direta (DAD; $n=18$ ) ou com derivação extra-anatômica (DEA; $n=3$ ). A média de idade foi 53,7 $\pm 7,3$ anos (variação 43-79 anos), sendo todos os pacientes tabagistas. Treze pacientes (62\%) apresentavam isquemia crítica. Dos pacientes submetidos à DAD, seis (33,4\%) necessitaram de revascularização associada (3 renais e 3 fêmoro-poplíteas). A mortalidade perioperatória foi nula. Quatro pacientes (22,2\%) desenvolveram disfunção renal transitória, mas apenas um paciente $(5,6 \%)$ necessitou de hemodiálise. O tempo mediano de seguimento foi de 17 meses (variação 2-29 meses), havendo apenas um óbito tardio, por cardiopatia isquêmica, sete meses após a cirurgia da aorta abdominal. Conclusão: A reconstrução aórtica é um método seguro para o tratamento de pacientes com OCAl, com baixas taxas de morbidade e mortalidade perioperatórias.
\end{abstract}

Palavras-chave: aorta abdominal; trombose; procedimentos cirúrgicos. 


\section{INTRODUCTION}

Chronic aortoiliac occlusion (CAIO) is a rare form of aortoiliac occlusive disease. ${ }^{1}$ Although reports had been published previously, ${ }^{2}$ it was Leriche who described in detail the condition's signs, symptoms, diagnosis and prognosis and the treatment possibilities for patients, even highlighting the possibility of treating them by resection of the affected segment and construction of a direct aortic bypass (DAB). ${ }^{3,4}$ Oudot \& Beaconsfield ${ }^{5}$ later described what was probably the first patient with CAIO to be treated with a DAB, constructed using a homologous graft. ${ }^{5}$ Over the years, several publications have reported good results after treatment of patients with CAIO using DAB, with mortality rates of less than $5 \%,{ }^{1,6-8}$ although other authors have described worse results, with mortality of up to $23 \% .{ }^{9}$ Alternative techniques such as the extra-anatomic bypass (EAD), using either the axillary artery or the thoracic aorta as graft donors, have been proposed by some authors, ${ }^{6,10}$ but the risks and complications of not directly treating the segment of the aorta that has thrombosis (primarily, the possibility of proximal propagation of the thrombus) mean that these procedures are less attractive and reserved for cases in which the patient does not offer clinical conditions to conduct the direct procedure.

With the widespread adoption of endovascular techniques to treat patients with aortoiliac occlusive disease, there are now also reports describing use of this technique with patients with CAIO. ${ }^{11}$ However, there is still little data and results have not yet been consolidated. Notwithstanding, in view of the existence of alternatives, it is important to document the results that are currently achieved when patients with CAIO are treated surgically, in order to be in a position to compare these data with the results of endovascular treatment. The objective of this study was therefore to describe our recent results after surgical treatment of patients with CAIO.

\section{METHODS}

\section{Patients}

We reviewed medical records for patients with CAIO who had been treated with DAB or EAD between November of 2011 and April 2014 by the vascular surgery service at the Santa Casa de Porto Alegre, Brazil. The project was approved by the Research Ethics Committee at the Santa Casa de Porto Alegre and all patients signed free and informed consent forms. Patients were excluded if they had acute aortoiliac arterial occlusion, as were patients with abdominal aortic aneurysm with thrombosis. In all cases, CAIO was diagnosed on the basis of clinical presentation and confirmed with computed tomography (CT) angiography.

\section{Preoperative characteristics of patients}

Data were collected on age, gender, comorbidities and clinical presentation for all patients. Comorbidities were defined as follows: smoking (current or previous cigarette smoking); hypertension (taking antihypertensive medication or arterial blood pressure $\geq 140 / 90 \mathrm{mmHg}$ ); ischemic heart disease (prior history of acute myocardial infarction and/or coronary angioplasty and/or angina); prior myocardial revascularization surgery; renal failure (serum creatinine $>2.0 \mathrm{mg} / \mathrm{dL}$ ); diabetes (taking hypoglycemic medication and/or insulin and/or fasting glycemia $>126 \mathrm{mg} / \mathrm{dL}$ ). With relation to clinical presentation, patients were categorized as follows: asymptomatic; intermittent claudication (pain in lower limbs when walking that eases at rest); or critical ischemia (presence of pain at rest and/or trophic lesion). For men, erectile dysfunction was defined as difficulty achieving or maintaining an erection during sexual activity.

\section{Types of aortic occlusion}

Chronic aortoiliac occlusions were classified according to the proximal limit of the thrombus, determined on the basis of the contrast column on the $\mathrm{CT}$ angiography examination, as follows: suprarenal occlusion (SRO): thrombosis compromising the suprarenal aorta, involving the orifices of both renal arteries, irrespective of superior mesenteric artery or celiac trunk involvement; inter-renal or transrenal occlusion (TRO): thrombus occluding the orifice of one of the renal arteries; juxtarenal occlusion (JRO): thrombosis extending to the level of the renal arteries, without compromising the orifices, but making suprarenal clamping necessary for surgical repair; and infrarenal occlusion (IRO): thrombosis with extension limited to the infrarenal aorta, with sufficient space to clamp the aorta below the renal arteries during surgery.

\section{Surgical technique and data}

All patients were operated on under general anesthesia. The procedures employed involved either DAB by aortic bifemoral bypass or EAD by axillarybifemoral bypass. Preoperative cardiac assessments were conducted according to routine procedure and patients with high surgical risk were treated 
using EAD. For cases treated with a DAB, access to the abdominal aorta was achieved via a xyphopubic incision. The pararenal aorta was accessed by dislocation or ligation of the left renal vein or by sectioning it and reanastomosing it. In cases in which the extent of the aortic thrombus was more proximal, both renal arteries were dissected and exposed, to avoid embolization and/or thrombosis. A $14 \times 7 \mathrm{~mm}$ bifurcated polyester synthetic graft was used for aortic surgery and $8 \mathrm{~mm}$ straight polyester grafts were used for extra-anatomic bypasses. Patients with trophic lesions and femoropopliteal occlusion were treated with infrainguinal revascularization during the same intervention, constructing a supracondylar femoropopliteal bypass, with a $6 \mathrm{~mm}$ polyester graft. Similarly, patients with renovascular hypertension (stenosis of the renal artery combined with renal dysfunction and/or difficult to control hypertension) were also treated with renal revascularization plus DAB. Cases of IRO were treated by construction of an aortic bifemoral bypass with placement of a bifurcated graft in the normal manner, clamping of the infrarenal aorta $2-3 \mathrm{~cm}$ from the lower renal artery, and end-to-side proximal anastomosis, with or without manual thrombectomy of the infrarenal aorta segment, as necessary. In other situations, those in which it was necessary to control the aorta more proximally (suprarenally), the left renal vein was displaced, ligated or sectioned and re-anastomosed, before clamping the suprarenal aorta and controlling the renal arteries (circumferential dissection and cerclage) to avoid embolization or thrombosis. In these cases, longitudinal aortotomy generally extends from the orifice of the lower renal artery to a point $1.5-2 \mathrm{~cm}$ from the juxtarenal aorta and manual thrombectomy is conducted, with or without aortorenal thrombus-endarterectomy. These grafts are also sutured end-to-side to the juxtarenal aorta, sometimes involving the orifices of the renal arteries. In some cases it is possible to clamp the suprarenal aorta, perform manual thrombectomy and then reposition the clamp close below the renal arteries to conduct the proximal anastomosis. In patients with thrombosis that extended higher, it was also necessary to conduct circumferential dissection of the superior mesenteric artery. All patients were given intravenous heparin $(100 \mathrm{UI} / \mathrm{kg})$ before clamping of the aorta. Routine procedure also included intravenous administration of mannitol (25 g) for renal protection and to stimulate diuresis. No preservation solutions were used to irrigate the kidneys during suprarenal clamping. Records were kept on duration of surgery, duration of renal ischemia, estimated blood loss and number of units of concentrated red blood cells transfused.

\section{Morbidity/mortality}

Mortality was defined while in hospital or within 30 days of surgery. Cardiovascular morbidity was defined as follows: angina or myocardial infarction, defined as chest pains combined with elevated troponin and abnormal electrocardiogram findings, and cardiac arrhythmia requiring treatment. Noncardiovascular morbidities recorded were as follows: respiratory insufficiency, defined as a need for prolonged mechanical ventilation ( $>72$ hours); reintubation or emergence of respiratory infection or atelectasis confirmed by clinical and radiological examination; and postoperative renal dysfunction, defined as an increase of at least $20 \%$ over baseline serum creatinine levels and considered transitory when levels returned to baseline or lower than $1.2 \mathrm{mg} / \mathrm{dL}$ by the time of hospital discharge. The following postoperative morbidities were also analyzed: all vascular cerebral events (strokes or transitory ischemic insults); gastrointestinal intercurrent conditions (for example, prolonged ileus, mesenteric and/or colonic ischemia, peptic disease); need for reoperation (bleeding, occlusion of the grafted segment); complications related to the surgical wound (hematoma, infection, dehiscence of walls), and other conditions (for example, deep venous thrombosis). Additionally, length of postoperative hospital stay and time spent in the intensive care unit were also recorded.

\section{Follow-up}

Patients were scheduled to attend their first consultations after surgery approximately 30 days after hospital discharge and were then followed for 6 months. Patency of bypasses was checked by clinical examination and imaging exams when necessary. Information was acquired for all patients about any intercurrent conditions, such as cardiovascular events, complications related to the graft, permanent renal dysfunction, requiring hemodialysis or not, and deaths from whatever cause.

\section{Statistical analysis}

Continuous variables are expressed as means \pm standard deviations or medians and variances. No specific statistical tests were performed and neither were survival or graft patency rates calculated, because of the small sample size and the narrow time frame covered by the study. 


\section{RESULTS}

\section{Preoperative characteristics of patients}

The patient sample comprised ten men $(47.6 \%)$ and 11 women $(52.4 \%)$, with a mean age of $53.7 \pm 7.3$ years (range: 43 to 79 ). All patients were smokers and the majority had hypertension $(66.7 \%)$. Occlusive diseases were common: 13 patients had critical ischemia of lower limbs $(62 \%)$, with pain at rest the most common symptom $(42.8 \%$ of the whole sample); five men (50\%) reported erectile dysfunction; and seven patients (33.4\%) exhibited occlusive femoropopliteal disease (Table 1).

\section{Types of occlusion}

The extent of abdominal aorta thrombosis was as follows: 12 patients had JRO (57.1\%); seven had IRO (33.4\%), and just two patients had TRO (9.5\%). During the period analyzed we did not treat any patients with SRO.

Table 1. Demographic characteristics, comorbidities and clinical presentation of patients treated for CAIO.

\begin{tabular}{lcc}
\hline \multicolumn{1}{c}{ Characteristics } & $\mathrm{n}$ & $\%$ \\
\hline Men & 10 & 47.6 \\
Women & 11 & 52.4 \\
Mean age (range:) & $53.7 \pm 7.3(43-79)$ & \\
Smoking & 21 & 100 \\
Arterial hypertension & 14 & 66.7 \\
Ischemic heart disease & 6 & 28.6 \\
Myocardial revascularization & 3 & 14.3 \\
Diabetes mellitus & 2 & 9.5 \\
Renal dysfunction & 2 & 9.5 \\
Limiting claudication & 8 & 38 \\
Critical ischemia & 13 & 62 \\
$\quad$ Pain at rest & 9 & 42.8 \\
$\quad$ Trophic lesion & 4 & 19 \\
Femoropopliteal occlusion & 7 & 33.4 \\
Erectile dysfunction (n=10) & 5 & 50 \\
\hline
\end{tabular}

\section{Surgical data}

Preoperative assessments showed that the majority of patients $(85.7 \%)$ did offer the clinical conditions needed to perform DAB. Clinical limitations and high surgical risk meant that the other three patients $(14.3 \%)$ were treated with EAD. The distribution of types of aortic occlusions and arterial bypasses is illustrated in Figure 1. A total of 18 patients were treated with $\mathrm{DAB}$ and it proved possible to perform proximal anastomosis with infrarenal clamping in ten of these patients $(55.5 \%)$. This subset of the DAB patients contained six patients with IRO and four with JRO, who were treated with brief suprarenal clamping, followed by longitudinal infrarenal aortotomy, thrombus-endarterectomy and repositioning of the clamp to an infrarenal position. For the other eight patients treated with DAB (44.5\%), it was necessary to apply suprarenal clamping during proximal anastomosis.

All of the patients treated with DAB were given aortic bifemoral bypasses $(n=18)$, and in seven of these the left renal vein was ligated to enable better exposure and dissection of the pararenal aorta. Five patients with IRO did not require any type of special maneuver for the left renal vein, other than identifying it during the surgical procedure. Two patients had a retroaortic left renal vein; in three patients the vein was sectioned and anastomosed; and in another case of JRO, it was only necessary to displace the left renal vein. Mean duration of surgery was $232 \pm 178.2$ minutes (range: $140-330$ minutes) and mean duration of renal ischemia was $22.4 \pm 12.1$ minutes (range: 18-44 minutes). Mean estimated blood loss was $586.6 \pm 369.7 \mathrm{~mL}$ (range: $250-1600 \mathrm{~mL}$ ). Mean number of units of concentrated red blood cells transfused was $0.94 \pm 1.02$ units (range: 0-3 units) (Table 2).

In three patients with renovascular disease (all with JRO), an additional bypass was constructed from the body of the bifurcated aortic graft to the left renal artery, using a $6 \mathrm{~mm}$ straight polyester

\begin{tabular}{|cccc|}
\hline SRO & TRO & JOR & IRO \\
$(n=0)$ & $(n=2)$ & $(n=12)$ & $(n=7)$ \\
& DAB (11) & DAB (6) \\
& EAD (1) & EAD (1) & EAD (1) \\
& & \\
\hline
\end{tabular}

Figure 1. Distribution of numbers of patients (in parentheses) by type of CAIO and type of surgery performed. SRO: suprarenal occlusion; TRO: inter-renal/transrenal occlusion; JRO: juxtarenal occlusion; IRO: infrarenal occlusion; DAB: direct aortic bypass; EAD: extra-anatomic bypass. 
graft in two patients and the great saphenous vein in the third. Three of the four patients with trophic lesions were treated with a unilateral supracondylar femoropopliteal bypass constructed from $6 \mathrm{~mm}$ synthetic polyester graft, in addition to the DAB, while the fourth, who was given an axillary-bifemoral bypass, only profundoplasty was conducted, with no femoropopliteal bypass, because of the limitations imposed by the patient's clinical condition, the distal arterial bed and the fact that the lesion was both superficial and small.

\section{Morbidity/mortality}

Mean number of days in hospital after surgery on the aorta was 9 days (range: 6-22 days) and median duration of stay in the intensive care unit was 2.5 days (range: $1-4$ days). None of the patients died, irrespective of whether treated with DAB or EAD. Surgical morbidities affected seven patients (33.4\%): one patient given an axillary-bifemoral bypass, who had a respiratory infection; and six patients in the DAB group, four of whom suffered postoperative renal dysfunction, which was transitory in three patients and permanent in one patient, who required hemodialysis after hospital discharge; one patient who suffered pulmonary atelectasis; and one with an infection of the surgical wound at the groin (Table 3). Both patients who had had respiratory complications responded well to clinical treatment with respiratory physiotherapy and antibiotics. The patient with an infected surgical wound in the groin also recovered well, with partial removal of the sutures from the skin, dressing and antibiotics.

\section{Follow-up}

After hospital discharge, patients were followed for a median of 17 months (range: 2-29 months). One patient with JRO, who had had prior renal dysfunction and was treated with a left renal bypass at the same time as the aortic surgery, died after 7 months of follow-up. The other two patients given aorta-left renal bypasses exhibited improved control of hypertension and stabilization of renal function. Vascular examinations did not detect any cases of occlusion of vessels, irrespective of whether patients were treated with DAB or with EAD. Patients who were treated with a femoropopliteal bypass during the same operation $(n=3)$, exhibited good recovery from trophic lesions, with complete healing of all lesions. The fourth patient with a trophic lesion, who had been treated with an axillary-bifemoral bypass without the infrainguinal bypass, also progressed well, with complete regression of the small trophic lesion.

Table 3. Results for patients with CAIO treated with abdominal aorta surgery $(n=18)$.

\begin{tabular}{lc}
\hline Postoperative hospital stay (median) & 9 days \\
ICU stay (median) & 2.5 days \\
Mortality & 0 \\
Morbidity & $6(33.4 \%)$ \\
Renal dysfunction & $4(22.3 \%)$ \\
Transitory & $3(16.7 \%)$ \\
Permanent (hemodialysis) & $1(5.6 \%)$ \\
Respiratory complication (atelectasis) & $1(5.6 \%)$ \\
Surgical wound infection & $1(5.6 \%)$ \\
\hline
\end{tabular}

Table 2. Surgical characteristics of patients treated for CAIO.

\begin{tabular}{lcc}
\hline \multicolumn{1}{c}{ Characteristics } & $\mathrm{n}$ & $\%$ \\
\hline Aortic-bifemoral bypass & 18 & 85.7 \\
Axillary -bifemoral bypass & 3 & 14.3 \\
Location aorta clamped & 18 & 55.6 \\
$\quad$ Infrarenal & 10 & 44.4 \\
$\quad$ Suprarenal & 8 & 100 \\
$\quad$ Left renal vein maneuver & 13 & 53.8 \\
$\quad$ Section and anastomosis & 7 & 23 \\
$\quad$ Retroaortic renal vein & 3 & 15.5 \\
$\quad$ Dislocation & 2 & 7.7 \\
Renal revascularization & 1 & 16.7 \\
Mean duration of surgery & 3 & 16.7 \\
Mean duration of renal ischemia & 3 & $232 \pm 178.2 \mathrm{minutes}$ \\
Estimated blood loss volume & & $22.4 \pm 12.1 \mathrm{minutes}$ \\
Mean number of units of concentrated red blood cells & & $586.5 \pm 369.7 \mathrm{~mL}$ \\
\hline
\end{tabular}




\section{DISCUSSION}

Chronic aortoiliac occlusion is an uncommon condition, occurring in up to $10 \%$ of patients treated for aortoiliac disease at some centers. ${ }^{1,8,9}$ Currently, a diagnosis of CAIO is still an absolute indication for surgical treatment in patients with aortoiliac occlusive disease, because the endovascular technique still suffers from limitations that impede adequate treatment of these patients, although there are already some recent studies that have reported promising results. ${ }^{11,12}$ On the other hand, as endovascular techniques are being more and more widely adopted for treatment of patients with aortoiliac occlusive disease, open surgery has come to be reserved for patients with more severe forms of occlusive disease, such as CAIO. García-Fernández et al..$^{13}$ found that $24 \%$ of a sample of patients operated on for aortoiliac occlusive disease had CAIO. Some recent studies are available, such as the very significant one published by West Jr et al., ${ }^{1}$ who described a series of 54 patients with CAIO seen over period of almost 12 years, and another recent one describing the experience gained treating 67 patients with CAIO over a period of 20 years. ${ }^{13}$ Even though our study covered a smaller series of patients $(n=21)$, treated over a period of approximately 2.5 years, we consider this to be a significant finding.

Generally, patients with CAIO are young, male and smokers. ${ }^{1,6-8}$ Our study bears out this tendency, with the exception of sex distribution, since we observed a higher proportion of females in our sample $(52.4 \%)$. This can be explained by the fact that the prevalence of smoking among young women in Brazil is at least $10 \% .{ }^{14}$ The most frequent clinical presentation in our study was critical ischemia, affecting $62 \%$ of the sample. In other reports the proportion of patients with critical ischemia appears to be lower, with the majority of patients presenting with intermittent claudication of the lower limbs. ${ }^{1,6,7,9}$ This difference may be the result of delayed clinical diagnosis or late referral of these patients for vascular treatments, with the result that the disease is more advanced when they are operated on.

The cause of CAIO is generally proximal progression of occlusive lesions that involves the aortoiliac bifurcation and but rarely affects the renal arteries. ${ }^{1,6}$ The majority of our patients presented with JRO (57.1\%) or IRO (33.4\%); and the findings of other studies are similar. ${ }^{1,7,9}$ West Jr et al. ${ }^{1}$ studied 20 patients with IRO and 34 with JRO in two separate groups and did not detect any significant differences between the groups in terms of demographic data or comorbidities, with the exception of the fact that the JRO group contained a higher proportion of patients with critical ischemia, which is possibly because when CAIO is located at higher sites, collateral circulation plays a less important role. All of our patients had CAIO secondary to atherosclerotic aortoiliac occlusive disease, but other causes of CAIO such as embolism, dissection and aortitis have also been described. ${ }^{1,15,16} \mathrm{We}$ did not see any cases of SRO, but Tapper et al. ${ }^{9}$ have described an interesting series of 66 patients with CAIO, in which 10 patients $(15 \%)$ had SRO, with a mortality rate of $9 \%$.

Some of our patients required special maneuvers to deal with the left renal vein. In the majority of these cases $(n=7)$ we chose permanent ligature. However, in another three patients who were also being treated with ipsilateral renal revascularization, we sectioned and reconstructed the vein in order to provide better renal venous return. Wang et al. ${ }^{17}$ have demonstrated that ligature of the left renal vein during surgery on the abdominal aorta is a safe procedure, because it does not cause permanent renal dysfunction in these patients, since left side renal venous drainage is also provided by the suprarenal and renolumbar veins.

Our sample included a subset of eight patients who required suprarenal clamping of the aorta, which involves a greater risk of renal dysfunction and death during the postoperative period. None of our patients died, but $22.3 \%$ of the patients treated with clamping or temporary control of the suprarenal aorta in order to conduct DAB suffered postoperative renal dysfunction. Other studies have reported good rates of mortality and morbidity after surgery on the aorta involving suprarenal clamping. ${ }^{18,19}$ West Jr et al. ${ }^{1}$ reported an $18.9 \%$ rate of renal dysfunction after surgery on patients with CAIO. In four patients with JRO, we were able to employ brief suprarenal clamping to conduct manual juxtarenal thrombectomy, before replacing the clamp in an infrarenal position in order to construct the proximal anastomosis. This classical and wellknown technique has been employed successfully and described by other authors. ${ }^{1,6-9}$

Our preference was to conduct aorto-bifemoral reconstruction in all of the patients treated with DAB. Some authors use an aortoiliac bypass, with the advantage that this approach avoids the inguinal exposure to conduct femoral anastomoses, thereby reducing the risk of complications such as infections of the surgical wound. ${ }^{20}$ Our preference for femoral anastomoses was due to the following factors: the presence of diffuse aortoiliac disease; technical simplicity (the femoral artery is more exposed 
than the external iliac); the need for infrainguinal revascularization in some cases; and the greater patency, which has been demonstrated in previous studies. ${ }^{13,21}$ In some cases, the decision to use femoral arteries for distal anastomoses was taken during surgery, when we found discrepancies between the state of the external iliac artery compared with what had been seen on angiotomography, with a greater degree of calcification or a lumen that was inadequate for distal anastomosis.

Six of our patients required unilateral renal revascularization $(n=3)$ or femoropopliteal bypasses $(n=3)$ in addition to the surgery on the aorta. Any additional procedures combined with surgery on the aorta can confer additional risk of morbidity and mortality, although some authors have reported good results. Mehta et al..$^{22}$ observed mortality rates of $5.7 \%$ among patients with aortoiliac occlusive disease subjected to renal revascularization in combination with DAB. Similarly, Chiesa et al. ${ }^{23}$ have reported good results after infrainguinal surgery combined with surgery on the abdominal aorta.

The good mortality and morbidity results observed in our study are in line with other previous studies. ${ }^{1,6-8,13}$ Surgical mortality among patients treated for CAIO ranges from 0 to $23 \% .^{1,6-9,13}$ The fact that we had zero surgical mortality in our sample can be partially explained by the fact that although these patients had significant occlusive arterial disease, they were also younger and, theoretically, had better functional capacity to allow them to withstand the procedure. Another important factor in achieving good results is the number of similar procedures the surgical team has conducted previously. Modrall et al. ${ }^{24}$ have already demonstrated that hospitals with higher volumes of aortic surgery have better postoperative results. Even since the rise to prominence of endovascular surgery, at our hospital we treat some patients with open surgery: in cases that present technical difficulties or contraindications against less invasive procedures. The most important complication directly related to the procedure (more than anything else, related to manipulation of the pararenal aorta) is postoperative renal dysfunction. Other authors have reported renal dysfunction rates ranging from $0 \%$ to $18.9 \% .^{1,6,7,9,13}$ Just one of our patients $(5.6 \%)$ required hemodialysis during the postoperative period. This patient had JRO, had a prior history of renal failure and was one of the cases also treated with renal revascularization. Some other studies have reported low rates of patients requiring hemodialysis during the postoperative period; ${ }^{18,25}$ while others report that up to $10 \%$ of patients with prior renal dysfunction subjected to surgery on the juxtarenal aorta required hemodialysis afterwards. ${ }^{26}$ West Jr et al. ${ }^{1}$ reported that $4.1 \%$ of patients with CAIO temporarily required hemodialysis during the postoperative period.

With relation to follow-up, there was one late death in our study, secondary to acute myocardial infarction 7 months after surgery on the aorta, and this was the same patient described in the previous paragraph. In view of the sample size, we did not calculate survival for our patient series, but earlier studies have reported 5-year survival rates of up to $76.3 \%$ in patients who had been operated on for CAIO., ${ }^{1,69}$ In our study, patency of aortic bifemoral grafts was verified in all patients by clinical examination and by testing for femoral pulses and also for distal pulses in cases in which infrainguinal bypasses had been constructed. West $\mathrm{Jr}$ et al. ${ }^{1}$ demonstrated $73.5 \%$ patency of aortic bifemoral bypasses over 6 years in patients who had had CAIO. One of the patients who underwent renal revascularization during the same operation $(n=3)$ died 7 months after surgery and control imaging examinations have not yet been conducted for the other two patients to test patency of renal bypasses. Notwithstanding, both of them have been exhibiting stable and normal serum creatinine and drug-based control of blood pressure has proved simple. Paty et al. ${ }^{27}$ have described good long-term results for patients treated with surgery of the aorta and renal arteries in combination. They reported a late renal dysfunction rate of just $3.1 \%$ and renal bypass patency was $96 \%$ at 5 years.

\section{CONCLUSIONS}

Open surgery for treatment of patients with CAIO has proven a safe method with low morbidity and zero mortality in our patients. These data will serve for future comparison with results obtained using endovascular techniques.

\section{REFERENCES}

1. West CA Jr, Johnson LW, Doucet L, et al. A contemporary experience of open aortic reconstruction in patients with chronic atherosclerotic occlusion of the abdominal aorta. J Vasc Surg. 2010;52(5):1164-72. http://dx.doi.org/10.1016/j.jvs.2010.05.112. PMid:20732782

2. Bell W. A case of thrombosis of the abdominal aorta. BMJ. 1896;2(1869):1227. http://dx.doi.org/10.1136/bmj.2.1869.1227. PMid:20756537

3. Leriche R. Des obliterations arterielles (obliteration de la terminason de l'aorta) comme causes des insuffisances cerulatiores des members inferieunes. Bull Soc Chir. 1923;49:1404-6. 
4. Leriche $\mathrm{R}$, Morel A. The syndrome of thrombotic obliteration of the aortic bifurcation. Ann Surg. 1948;127(2):193-206. http:// dx.doi.org/10.1097/00000658-194802000-00001. PMid:17859070

5. Oudot J, Beaconsfield P. Thrombosis of the aortic bifurcation treated by resection and homograft replacement; report of five cases. AMA Arch Surg. 1953;66(3):365-74. http://dx.doi. org/10.1001/archsurg.1953.01260030380012. PMid:13030063

6. Ligush J Jr, Criado E, Burnham SJ, Johnson G Jr, Keagy BA. Management and outcome of chronic atherosclerotic infrarenal aortic occlusion. J Vasc Surg. 1996;24(3):394-404, discussion 404-5. http://dx.doi.org/10.1016/S0741-5214(96)70195-7.PMid:8808961

7. Traverso LW, Baker JD, Dainko EA, Machleder HI. Infrarenal aortic occlusion. Ann Surg. 1978;187(4):397-401. http://dx.doi. org/10.1097/00000658-197804000-00009. PMid:646479

8. Liddicoat JE, Bekassy SM, Dang MH, De Bakey ME. Complete occlusion of the infrarenal abdominal aorta: management and results in 64 patients. Surgery. 1975;77(3):467-72. PMid:1124502.

9. Tapper SS, Jenkins JM, Edwards WH, Mulherin JL Jr, Martin RS 3rd, Edwards WH Jr. Juxtarenal aortic occlusion. Ann Surg. 1992;215(5):443-9, discussion 449-50. http://dx.doi. org/10.1097/00000658-199205000-00006. PMid:1616381

10. Frantz SL, Kaplitt MJ, Beil AR Jr, Stein HL. Ascending aortabilateral femoral artery bypass for the totally occluded infrarenal abdominal aorta. Surgery. 1974;75(3):471-5. PMid:4811344.

11. Moise MA, Alvarez-Tostado JÁ, Clair DG, et al. Endovascular management of chronic infrarenal aortic occlusion. J Endovasc Ther. 2009;16(1):84-92. http://dx.doi.org/10.1583/08-2526.1. PMid:19281286

12. Yuan J, Bao J, Zhao Z, Feng X, Lu Q, Jing Z. Endovascular therapy for long-segment atherosclerotic aortoiliac occlusion. J Vasc Surg. 2014;59(3):663-8. PMid:24239521.

13. García-Fernández F, Marchena Gómez J, Cabrera Morán V, Hermida $M$, Sotgiu E, Volo Pérez G. Chronic infrarenal aortic occlusion: predictors of surgical outcome in patients undergoing aortobifemoral bypass reconstruction. J Cardiovasc Surg (Torino). 2011;52(3):371-80. PMid:21577192.

14. Centers for Disease Control and Prevention. Current tobacco use and secondhand smoke exposure among women of reproductive age-14 countries, 2008-2010. MMWR Morb Mortal Wkly Rep. 2012;61(43):877-82. PMid:23114255.

15. Tan CY, Qin W, Zhao Y, Yang Y, Huang ZX, Liu Y. A case of isolated aorta occlusion caused by Takayasu arteritis. J Clin Rheumatol. 2013;19(4):209-10. http://dx.doi.org/10.1097/ RHU.0b013e318289dd00. PMid:23669795

16. Crawford JD, Perrone KH, Wong VW, et al. A modern series of acute aortic occlusion. J Vasc Surg. 2014;59(4):1044-50. http:// dx.doi.org/10.1016/j.jvs.2013.10.080. PMid:24393282

17. Wang L, Xin SJ, Song Z, Zhang J. Left renal vein division during open surgery of abdominal aortic disease: a propensity score-matched case-control study. Eur J Vasc Endovasc Surg. 2013;46(2):227-31. http://dx.doi.org/10.1016/j.ejvs.2013.04.028. PMid:23743276

18. Tsai S, Conrad MF, Patel VI, et al. Durability of open repair of juxtarenal abdominal aortic aneurysms. J Vasc Surg. 2012;56(1):27. http://dx.doi.org/10.1016/j.jvs.2011.12.085. PMid:22534029

19. Dubois L, Durant C, Harrington DM, Forbes TL, Derose G, Harris JR. Technical factors are strongest predictors of postoperative renal dysfunction after open transperitoneal juxtarenal abdominal aortic aneurysm repair. J Vasc Surg. 2013;57(3):648-54 http://dx.doi.org/10.1016/j.jvs.2012.09.043. PMid:23312936

20. York JW, Johnson BL, Cicchillo M, Taylor SM, Cull DL, Kalbaugh C. Aortobiiliac bypass to the distal external iliac artery versus aortobifemoral bypass: a matched cohort study. Am Surg. 2013;79(1):61-6. PMid:23317613.

21. Sen I, Stephen E, Agarwal S. Clinical profile of aortoiliac occlusive disease and outcomes of aortobifemoral bypass in India. I Vasc Surg. 2013;57(2, Suppl):20S-5S. http://dx.doi.org/10.1016/j. jvs.2012.06.113. PMid:23336851

22. Mehta M, Darling RC 3rd, Roddy SP, et al. Outcome of concomitant renal artery reconstructions in patients with aortic aneurysm and occlusive disease. Vascular. 2004;12(6):381-6 http://dx.doi.org/10.2310/6670.2004.00045. PMid:15895762

23. Chiesa R, Marone EM, Tshomba Y, Logaldo D, Castellano R, Melissano $G$. Aortobifemoral bypass grafting using expanded polytetrafluoroethylene stretch grafts in patients with occlusive atherosclerotic disease. Ann Vasc Surg. 2009;23(6):764-9. http:// dx.doi.org/10.1016/j.avsg.2009.01.004. PMid:19540713

24. Modrall JG, Rosero EB, Chung J, et al. Defining the type of surgeon volume that influences the outcomes for open abdominal aortic aneurysm repair. J Vasc Surg. 2011;54(6):1599-604. http://dx.doi org/10.1016/j.jvs.2011.05.103. PMid:21962924

25. Knott AW, Kalra M, Duncan AA, et al. Open repair of juxtarena aortic aneurysms (JAA) remains a safe option in the era of fenestrated endografts. J Vasc Surg. 2008;47(4):695-701. http:// dx.doi.org/10.1016/j.jvs.2007.12.007. PMid:18272317

26. West CA, Noel AA, Bower TC, et al. Factors affecting outcomes of open surgical repair of pararenal aortic aneurysms: a 10-year experience. J Vasc Surg. 2006;43(5):921-7, discussion 927-8. http:// dx.doi.org/10.1016/j.jvs.2006.01.018. PMid:16678684

27. Paty PS, Darling RC 3rd, Lee D, et al. Is prosthetic renal artery reconstruction a durable procedure? An analysis of 489 bypass grafts. J Vasc Surg. 2001;34(1):127-32. http://dx.doi.org/10.1067/ mva.2001.112697. PMid:11436085

Correspondence Márcio Luís Lucas

Rua Passo da Pátria, 515/1001 - Bela Vista CEP 90060-460 - Porto Alegre (RS), Brazil Tel.: +55 (51) 91968186 / (51) 33331642 E-mail:mlucasvascular@hotmail.com

Author information MLL - Vascular surgeon. Preceptor, Vascular Surgery Service, Santa Casa de Misericórdia de Porto Alegre. LD - Former resident in Vascular Surgery, Universidade Federal de Ciências da Saúde de Porto Alegre (UFCSPA) and Santa Casa de Misericórdia de Porto Alegre. EL and NEJr - Adjunct professors of Vascular Surgery, Universidade Federal de Ciências da Saúde de Porto Alegre (UFCSPA). Preceptors, Vascular Surgery Service, Santa Casa de Misericórdia de Porto Alegre. NA - Adjunct professor of Vascular Surgery and Chief of the Vascular Surgery Service, Santa Casa de Misericórdia de Porto Alegre.

Author contributions Conception and design: MLL, LD, EL, NEJr, NA Analysis and interpretation: MLL, LD, EL, NEJr, NA Data collection: MLL, LD Writing the article: MLL Critical revision of the article: MLL, LD, EL, NEJr, NA Final approval of the article*: MLL, LD, EL, NEJr, NA Statistical analysis: MLL, LD Overall responsibility: MLL

*All authors have read and approved of the final version of the article submitted to J Vasc Bras. 